\title{
Memória editorial e temática da Editora Universitária da UFPE (1955-2014)
}

\author{
Editorial and Thematic Memory of the University Press of UFPE (1955-2014)
}

\begin{abstract}
Murilo Artur Araújo da Silveira Doutor em Comunicação e Informação pela Universidade Federal do Rio Grande do Sul - UFRGS, Brasil. Professor Adjunto no Departamento de Ciência da Informação da Universidade Federal de Pernambuco - UFPE,

Brasil.

E-mail: muriloas@gmail.com

ORCID: https://orcid.org/0000-0002-9708-6001
\end{abstract}

Leilah Santiago Bufrem

Doutora em Ciências da Comunicação pela Escola de Comunicação e Artes da Universidade de São Paulo ECA/USP, Brasil.

Professora visitante no Programa de Pós-graduação em Ciência da Informação da Universidade Federal da Paraíba - UFPB, Professora visitante sênior no Programa de Pós-Graduação em Ciência da Informação da Universidade Federal de Pernambuco - UFPE e Professora permanente no Programa de Pós-Graduação em Educação da Universidade Federal do Paraná - UFPR, Brasil.

E-mail: santiagobufrem@gmail.com ORCID: http://orcid.org/0000-0002-3620-0632

\section{Resumo}

Apresenta o percurso editorial da Editora Universitária da Universidade Federal de Pernambuco (EDUFPE) e a configuração temática das publicações em sessenta anos de sua existência. Tem como objetivo central reconstruir a linhagem temática e editorial da EDUFPE por meio dos itens registrados no catálogo de publicações do período de 1955 a 2014. A análise se concentra em 2.225 registros bibliográficos e utiliza os métodos cientométrico e análise de assunto. Apresenta como principais resultados: a) a trajetória editorial da Editora é marcada por três momentos históricos; e b) há predominância de publicações das Ciências Humanas e das Letras e Artes, no seu catálogo histórico. Conclui que o percurso da EDUFPE está diretamente vinculado ao de sua mantenedora ao longo do tempo.

Palavras-chave: Editoras Universitárias. Produção bibliográfica. Memória editorial. Tendências temáticas. Editora Universitária da UFPE.

\begin{abstract}
It presents the editorial trajectory of the University Press of UFPE and thematic configuration of publications in sixty years. Its main objective is to reconstruct the thematic and editorial lineage of the University Press of UFPE (EDUFPE) through the items recorded in the catalog of publications from 1955 to 2014 . The analysis focuses on 2,225 bibliographic records through the scientometric and subject analysis methods. The main results are: a) editorial trajectory marked by three historical moments; and b) predominance of publications in the Humanities and Letters and Arts. It concludes that the trajectory of EDUFPE is directly linked to that of its maintainer over time.
\end{abstract}

Keywords: University presses. Bibliography publications. Editorial memory. Thematic trends. University press of UFPE. 


\section{Introdução}

A prática editorial universitária no Brasil apresenta aspectos peculiares, discutidos por Bufrem (2015). A experiência brasileira iniciou na década de 1960, quando projetos editoriais foram evoluindo a partir dos serviços gráficos, das imprensas universitárias, aos poucos transformadas em editoras. Assim concebidas, como órgãos que selecionam, produzem e divulgam a produção acadêmica, as editoras universitárias brasileiras foram sendo estruturadas, formando conselhos, formalizando seus regimentos e estabelecendo linhas editoriais, compatíveis com a política deles emanada. Esses aspectos adquirem um valor específico no mercado dos bens simbólicos, razão pela qual essas editoras distinguem-se entre as demais editoras no setor livreiro.

As editoras universitárias caracterizam-se pela especificidade do seu trabalho, contribuindo para o que se denomina de "bibliodiversidade", o que nos leva a argumentar favoravelmente à sua criação e à divulgação de sua produção para além dos muros da academia. A elas cabe divulgar o que se pesquisa e se inova nas Instituições de Ensino Superior, mas também o que se deve preservar como contribuição à memória e à história local; divulgar as produções de valor universal, mas também aquelas relativas aos valores locais e regionais; os conteúdos significativos para a ciência e a tecnologia, e ainda as humanidades e as artes; privilegiar não somente a produção de autores consagrados, mas também os novos autores e pesquisadores nem sempre reconhecidos ou consagrados a ponto de se tornarem atrativos para as empresas editoriais.

Ao analisar a situação da editoração no Mercosul no final dos anos 1990, McCarthy (1997) considerou o caso brasileiro como peculiar, linguisticamente integrado, marcado por um mercado amplo de distribuição e consumo, assim como considerou e que a produção significativa de livros era decorrente das editoras comerciais. O autor menciona que, em relação às editoras comerciais, as universitárias têm potencial para ampliar e diversificar a oferta por estarem inseridas em instituições nas quais a produção de conhecimento é fértil, dinâmica, diversa e orientada a públicos distintos (McCARTHY, 1997). Entretanto, Gusmão e McCarthy reforçam que as editoras universitárias são importantes para a universidade e a sociedade em relação simbiótica, porque 
elas contribuem efetivamente para o enriquecimento da produção editorial no país, considerando-se que, dificilmente estes documentos conseguiriam espaço ou patrocínio para publicação através de editoras privadas. Primeiro, devido ao caráter acadêmico e, segundo, pela pequena tiragem por edição, que eleva o custo por unidade (1996, p. 13).

A noção de campo intelectual apresentada por Bourdieu e Passeron (2012), para significar o sistema de relações entre produtores e seus produtos, bem como suas posições (autores, editores, críticos, entre outros), explica, grosso modo, a configuração editorial no Brasil no que tange à ruptura do sistema reprodutivo da ciência. Neste cenário de bens simbólicos, as editoras universitárias são organizadas com base na construção interativa de suas práticas, a partir de seu cotidiano cultural e das relações de força nele atuantes.

Assim, graças à sua peculiar atuação, as editoras universitárias têm hoje lugar assegurado no competitivo mercado editorial brasileiro, contribuindo significativamente como divulgadoras de inovações, críticas e análises que problematizam conteúdos de interesse público ou social, como promotoras de estudos originais e traduções que dificilmente seriam publicados por editoras do mercado, assim como de obras complexas, cujo esforço editorial e financeiro para sua publicação nem sempre permitem um retorno do investimento de modo rápido.

Em continuidade às atividades de compilação das publicações editadas pela Editora Universitária da Universidade Federal de Pernambuco (EDUFPE), alunos e professores do Departamento de Ciência da Informação da UFPE vêm identificando e organizando os itens por ela publicados, de 2006 a 2015. O documento está em fase de finalização e com organização descritiva e temática distinta dos documentos dos catálogos de 1996 e 2006 (UFPE, 1996; 2006). A apresentação dos registros nestes repertórios se deu pela diversidade e pluralidade de temas, amplitude e alcance dos elementos autorais, além da fecunda e expressiva dimensão intelectual presente e subjacente à produção científica de sessenta anos. Nesse sentido, a organização deste catálogo priorizou os elementos temáticos das obras, sem desprezo daqueles presentes nos outros catálogos, tais como os arranjos cronológico e onomástico.

Por sua natureza retrospectiva, os repertórios bibliográficos (incluindo os catálogos) resgatam os fragmentos de informação conhecidos e esquecidos, inserindo-os em contextos e abordagens temporais e espaciais adequados, com o propósito de revelar a dinâmica do conhecimento publicado (FONSECA, 1964; BUFREM, 1993; HARTNESS, 1999; 2014). Contudo, esses instrumentos merecem ser analisados e interpretados à luz dos contextos e das 
circunstâncias que propiciaram a produção e comunicação do conhecimento, como forma de revelar diacronicamente o panorama bibliográfico dos pontos de vista autoral, editorial, institucional, temático e temporal (SILVEIRA et al., 2009).

No tocante à expressiva e diversificada produção científica publicada pela EDUFPE e às circunstâncias e abordagens presentes na organização do catálogo em fase final de elaboração, apresenta-se como questão de pesquisa: qual a configuração temático-editorial das publicações da EDUFPE de 1955 a 2015? A despeito da existência (e/ou ausência) de políticas ao longo do tempo, admitem-se três momentos editoriais para a EDUFPE e que resultam em três momentos temáticos distintos e notadamente marcados por elementos contextuais dos respectivos períodos.

A justificativa central desta pesquisa se ampara nos estudos de reconstrução da memória por meio das fontes disponíveis e acessíveis para prover outras formas de conhecimento do percurso trilhado pelos atores e instituições envolvidas (THIESEN, 2013). Sob a ótica da Ciência da Informação, esses instrumentos bibliográficos permitem remontar a linhagem histórica e científica, resgatar fragmentos percebidos e esquecidos que refletem a vocação institucional e fornecer elementos pontuais sobre a dinâmica de produção do conhecimento nos diversos períodos. Nesse espectro de alcance, a pesquisa se justifica porque busca:

a) traçar o perfil vocacional da EDUFPE ao longo de sessenta anos de atuação;

b) revelar a linhagem editorial e temática da instituição em seus marcos editoriais em seis décadas.

Face ao exposto, o objetivo central desta pesquisa é reconstruir a linhagem temática e editorial da Editora Universitária da UFPE (EDUFPE) por meio dos itens registrados no catálogo de publicações do período de 1955 a 2014. Desdobram-se como objetivos específicos são:

a) definir os marcos editoriais estabelecidos pela EDUFPE por meio de suas gestões ao longo dos anos;

b) estabelecer os percursos temáticos das publicações editadas e publicadas segundo os marcos editoriais da EDUFPE. 


\section{Procedimentos metodológicos}

Esta contribuição caracteriza-se por se constituir em combinação de estudo cientométrico com análise de assunto, configurando-se como descritiva, com exploração minuciosa dos dados resultantes das pesquisas bibliográfica e documental. No que se refere à coleta e organização dos dados, a pesquisa se deteve em técnicas de tratamento temático e descritivo e de análise histórica. Quanto à análise e discussão dos dados, as técnicas bibliométricas e de representação cartográfica foram utilizadas para apresentação dos resultados.

No período entre agosto 2017 a julho de 2018 foram executadas todas as atividades, a seguir discriminadas.

\section{Etapa 1: Coleta e organização dos dados}

1.1: Coleta e análise documental dos relatórios de gestão e das propostas e planejamentos da EDUFPE;

1.2: Levantamento das comissões editoriais existentes (Comissão Editorial e Conselho Técnico-Administrativo) e de suas atribuições;

1.3: Inclusão dos dados descritivos e temáticos em uma planilha do software Microsoft Excel presentes no catálogo de acordo com os momentos editoriais (período 1955-2014);

1.4: Correção dos dados descritivos e temáticos;

1.5: Apresentação dos momentos editoriais e da produção técnico-científica do período (19552014).

\section{Etapa 2: Análise e discussão dos dados}

2.1: Verificação dos momentos editoriais e as publicações em relação ao tempo;

2.2: Análise dos momentos editoriais e as publicações em relação às comissões editoriais;

2.3: Discussão dos momentos e políticas da EDUFPE ao longo dos sessenta anos, considerando os aspectos temáticos e editoriais; 
2.4: Estabelecimento do percurso histórico da EDUFPE em relação ao tempo e às políticas editoriais e às temáticas e os momentos editoriais.

\section{Resultados e discussão}

A apresentação e a discussão dos resultados encontrados fundamentam-se em duas perspectivas: a) a primeira contempla a análise temática ao longo de sessenta anos de atividades da EDUFPE; e b) a segunda se reporta para a análise editorial do percurso histórico da Editora.

\subsection{Análise temática}

Todas as obras publicadas pela EDUFPE foram categorizadas conforme a distribuição temática da Tabela de Áreas do Conhecimento do Conselho Nacional de Desenvolvimento Científico e Tecnológico (CNPq), as quais se discriminam a seguir a partir do Quadro 1.

\begin{tabular}{|c|} 
Quadro 1 - Áreas do Conhecimento do CNPq \\
Áreas do Conhecimento \\
Ciências Exatas e da Terra \\
\hline Ciências Biológicas \\
\hline Engenharias \\
\hline Ciências da Saúde \\
\hline Ciências Agrárias \\
\hline Ciências Sociais Aplicadas \\
\hline Ciências Humanas \\
\hline Linguística, Letras e Artes \\
\hline Fonte: CNPq, [2000]
\end{tabular}

Após a categorização das publicações da EDUFPE, os itens foram agrupados por décadas nos seguintes intervalos: a) 1955-1964; b) 1965-1974; c) 1975-1984; d) 1985-1994; e) 1995-2004; e f) 2005-2014. Cabe registrar que a disposição do tempo por décadas leva em consideração as primeiras atividades editoriais pela EDUFPE quando se denominava como Imprensa Universitária e tinha outros propósitos institucionais junto à Administração Central da Universidade Federal de Pernambuco (UFPE).

O agrupamento proposto tem a função de sinalizar não somente a distribuição temática do período, mas também de servir de parâmetro para a distinção dos momentos editoriais da 
EDUFPE. Enfatiza-se ainda que a categorização das obras editadas e publicadas pela Editora e o estabelecimento da distribuição por década conduzirão a discussão a seguir.

O levantamento inicial das publicações foi possível por meio dos catálogos de publicações de 40 e 50 anos da EDUFPE, por ele editados e publicados (UFPE, 1996; 2006). Por se basear em dois instrumentos bibliográficos que sofreram atualizações desde 1996, o arranjo alfabético dos catálogos publicados pela editora tornou-se secundário. Para Cunha (2001), os arranjos dos repertórios bibliográficos são importantes porque enfatizam os propósitos da compilação, favorecem a visualização da organicidade proposta e sinalizam a singularidade e completude os documentos listados. Assim, o próximo catálogo, em vias de publicação, terá os arranjos cronológico e sistemático como princípio de organização.

O total de itens presentes após a organização perfaz 2.225 publicações, editadas com o selo editorial da EDUFPE e identificadas ao longo de 60 anos de atividades. A distribuição das publicações editadas pela EDUFPE de 1955 a 2014 é exibida por meio do Gráfico 1.

Gráfico 1 - Distribuição das publicações da EDUFPE (1955-2014)

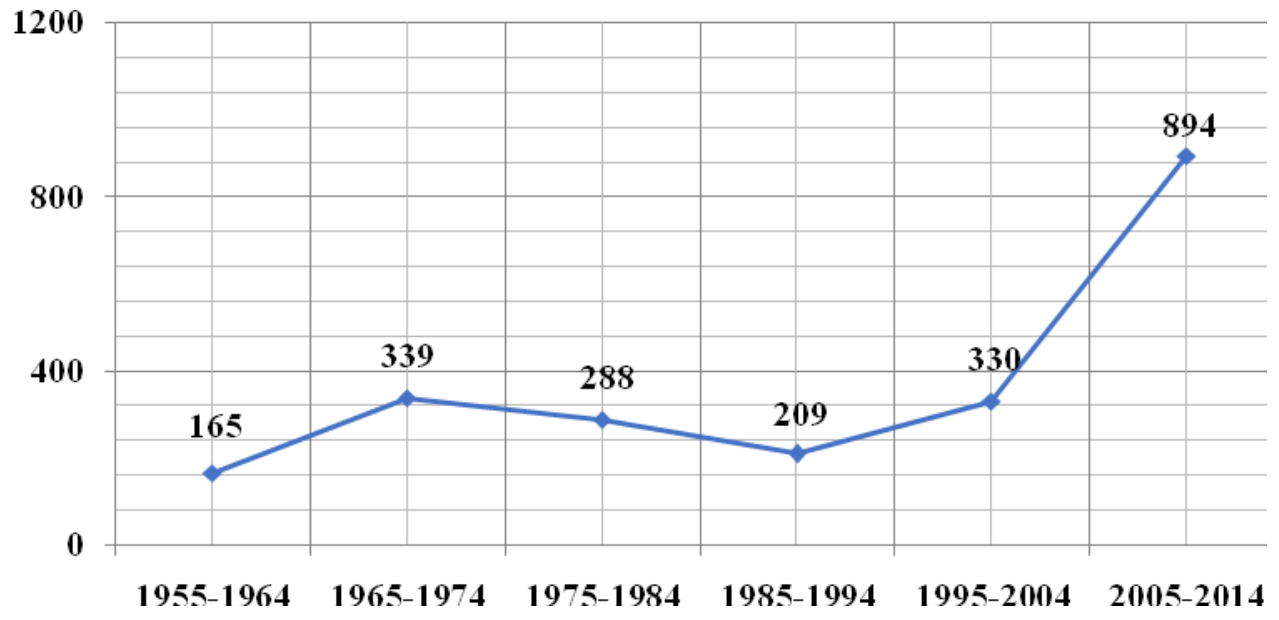

Fonte: Dados da pesquisa, 2019.

Os números presentes no Gráfico 1 sinalizam os momentos temporais referentes às 2.225 obras publicadas pela EDUFPE em 60 anos, os quais destacam:

a) Os aclives e declives acentuados de publicações editadas nas décadas de 1985-1994 e 2005-2014, respectivamente;

b) O decréscimo de publicações das duas décadas de 1975-1984 e 1985-1994; e

c) O aumento significativo compreendido entre as décadas de 1995-2004 e 2005-2014. 
No tocante às publicações segundo as áreas do conhecimento, o Gráfico 2 ilustra a distribuição no período da pesquisa.

Gráfico 2 - Distribuição das publicações da EDUFPE por Áreas do Conhecimento

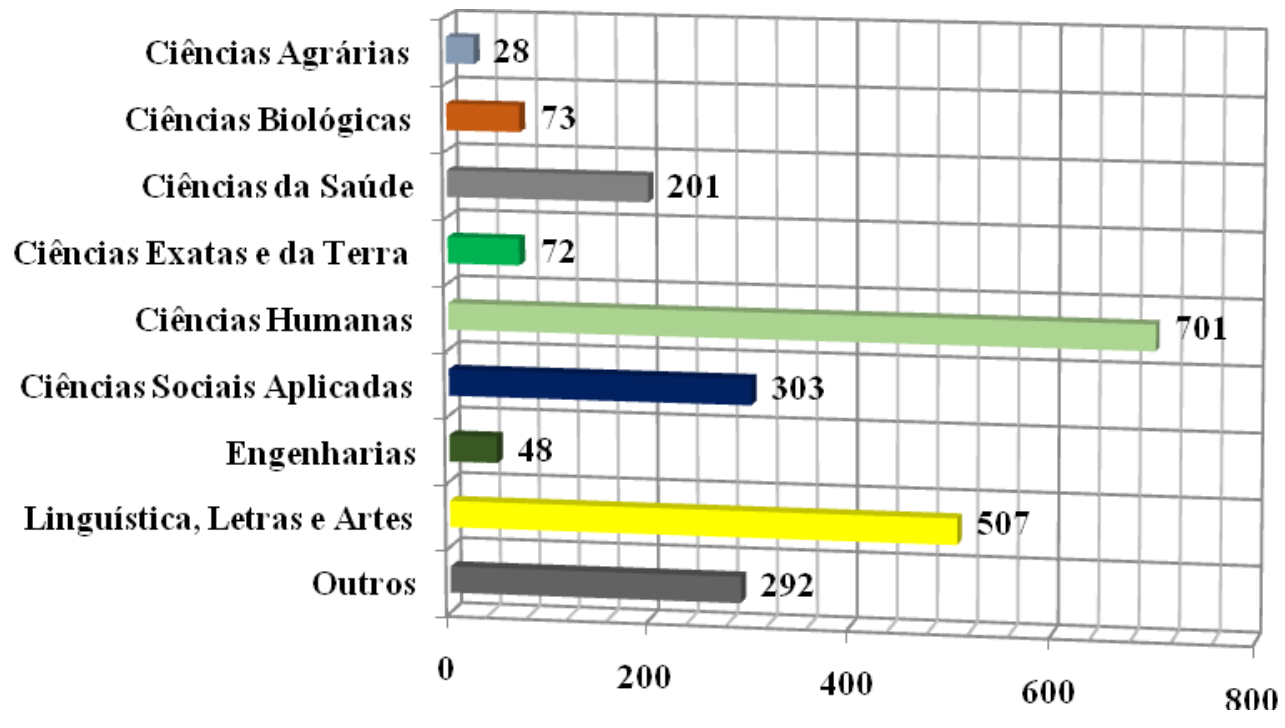

Fonte: Dados da Pesquisa, 2019.

A representação gráfica acima (Gráfico 2) demonstra os números de itens publicados pela Editora em nove categorias, no período de 1955 a 2014. Os principais destaques que se visualizam no gráfico são:

a) as posições privilegiadas das áreas Ciências Humanas e Linguística, Letras e Artes, com 701 e 507 publicações, respectivamente;

b) as posições de quatro áreas do conhecimento com menos de 100 obras publicadas no período: Ciências Agrárias (28), Ciências Biológicas (73), Ciências Exatas e da Terra (72) e Engenharias (48);

c) as posições intermediárias das áreas Ciências da Saúde e Ciências Sociais Aplicadas, com 201 e 303 itens publicados, respectivamente; e

d) a posição da categoria 'Outros' com 292 publicações.

Em tempo, destaca-se que a categoria 'Outros' foi estabelecida para agrupar as publicações oficiais, os planos e projetos de gestão da UFPE, os discursos oficiais de reitores e demais membros da administração, entre outros itens impossibilitados de categorização. 
Registra-se ainda que alguns títulos que não se enquadraram nas áreas e seus respectivos domínios foram categorizados como 'Outros'.

Para complementar a análise temática da EDUFPE, apresenta-se a Tabela 1 com a distribuição das obras editadas e publicadas por décadas, segundo as áreas do conhecimento do CNPq (Quadro 1).

Tabela 1 - Distribuição por décadas das publicações da EDUFPE por Áreas do Conhecimento

\begin{tabular}{|ccccccccc|}
\hline $\begin{array}{c}\text { Áreas do } \\
\text { Conhecimento }\end{array}$ & $\mathbf{1 9 5 5 -}$ & $\mathbf{1 9 6 5 -}$ & $\mathbf{1 9 7 5 -}$ & $\mathbf{1 9 8 5 -}$ & $\mathbf{1 9 9 5 -}$ & $\mathbf{2 0 0 5 -}$ & Total \\
\cline { 2 - 6 } $\begin{array}{c}\text { Ciências } \\
\text { Agrárias }\end{array}$ & 0 & 0 & 6 & 0 & 5 & 17 & $\mathbf{2 8}$ \\
$\begin{array}{c}\text { Ciências } \\
\text { Biológicas }\end{array}$ & 9 & 16 & 2 & 11 & 13 & 22 & $\mathbf{7 3}$ \\
\hline $\begin{array}{c}\text { Ciências da } \\
\text { Saúde }\end{array}$ & 38 & 25 & 20 & 12 & 29 & 77 & $\mathbf{2 0 1}$ \\
\hline $\begin{array}{c}\text { Ciências Exatas } \\
\text { e da Terra }\end{array}$ & 6 & 14 & 9 & 12 & 15 & 16 & $\mathbf{7 2}$ \\
\hline $\begin{array}{c}\text { Ciências } \\
\text { Humanas }\end{array}$ & 19 & 55 & 117 & 44 & 117 & 349 & $\mathbf{7 0 1}$ \\
\hline $\begin{array}{c}\text { Ciências Sociais } \\
\text { Aplicadas }\end{array}$ & 29 & 53 & 43 & 37 & 36 & 105 & $\mathbf{3 0 3}$ \\
\hline $\begin{array}{c}\text { Engenharias } \\
\text { Linguística, }\end{array}$ & 6 & 0 & 3 & 2 & 7 & 30 & $\mathbf{4 8}$ \\
\hline Letras e Artes & 4 & 13 & 49 & 68 & 95 & 278 & $\mathbf{5 0 7}$ \\
\hline $\begin{array}{c}\text { Outros } \\
\text { Total }\end{array}$ & 54 & 163 & 39 & 23 & 13 & 0 & $\mathbf{2 9 2}$ \\
\hline & $\mathbf{1 6 5}$ & $\mathbf{3 3 9}$ & $\mathbf{2 8 8}$ & $\mathbf{2 0 9}$ & $\mathbf{3 3 0}$ & $\mathbf{8 9 4}$ & $\mathbf{2 2 2 5}$ \\
\hline
\end{tabular}

Antes de iniciar a discussão, torna-se oportuno relativizar algumas distribuições tendo como parâmetro os números totais de publicações por década, situados na parte inferior da Tabela 1. A representação acima aponta como se apresentou a distribuição nas décadas das obras editadas e publicadas pela EDUFPE com base nas áreas do conhecimento no CNPq, com destaque para:

a) a inconstância de publicações das áreas Ciências Agrárias e Engenharias ao longo das seis décadas;

b) a constância de obras publicadas nas áreas Ciências Biológicas, Ciências da Saúde e Ciências Exatas e da Terra nas cinco primeiras décadas;

c) o aumento significativo de obras publicadas na área de Ciências Humanas, em especial nas décadas 1975-1984 e 1995-2004, quando o número total de publicações duplicou em relação às décadas anteriores (1965-1974 e 1985-1994, respectivamente); 
d) os aclives e declives de publicações da área Ciências Sociais Aplicadas ao longo das seis décadas;

e) o crescimento gradual de obras publicadas da área Linguística, Letras e Artes nas seis décadas;

f) o decréscimo de itens bibliográficos da categoria Outros nas últimas quatro décadas.

É necessário registrar que na última década, devido ao crescimento acentuado de publicações, seis áreas do conhecimento obtiveram um desempenho significativo em relação à década anterior, com destaque para três: Ciências Humanas, Ciências Sociais Aplicadas e Linguística, Letras e Artes.

\subsection{Análise editorial}

A constituição da EDUFPE no âmbito de sua mantenedora remonta ao período da criação da Universidade do Recife, em 1946, quando foi instituída a Imprensa Universitária, em substituição ao Serviço de Encadernação. Suas primeiras atividades datam de 1955 com o objetivo de auxiliar a Administração Central da Universidade do Recife nas atividades de impressão. Em 1965, a Universidade do Recife passa a se denominar Universidade Federal de Pernambuco (UFPE) e, somente em 1968, a Imprensa Universitária é transformada em órgão suplementar. Em 1972, a Editora Universitária da UFPE é instituída com o propósito de tornála autossuficiente e atender as novas demandas dos Ministérios do Planejamento e da Educação e Cultura no processo de dinamização das imprensas universitárias brasileiras (GUSMÃO; MCCARTHY, 1996).

O processo de dinamização das imprensas universitárias previa o modelo de implantação de editoras de modo a viabilizar a autossuficiência econômica e financeira, bem como a criação dos conselhos editoriais com vistas à avaliação das obras a serem publicadas. Para Gusmão e McCarthy (1996), a alteração de status da imprensa para editora não alterou suas ações e práticas no que tange às publicações, pois sua atuação no Recife era pujante a ponto de prejudicar as atividades editoriais das empresas privadas do setor. Entretanto, a tentativa de ampliar e fortalecer estruturas mais adequadas ao trabalho editorial também se faz presente nas informações sobre a Editora da Universidade Federal de Pernambuco, levantadas 
por Bufrem (2015, p. 363) e relacionadas ao investimento na automação e no redimensionamento de suas técnicas de gestão.

Para o levantamento das atividades editoriais previu-se a consulta aos relatórios de gestão, às atas dos conselhos, aos planos de ação, entre outros. Contudo, não foi possível ter acesso a eles. Dessa forma, buscaram-se outros elementos para a realização dessa etapa. Já para o conhecimento das comissões editoriais ao longo do tempo, recorreu-se às informações contidas no verso da folha de rosto das obras publicadas e disponíveis na livraria da Editora.

Sobre os aspectos gerenciais e o percurso trilhado pela unidade acadêmica e seus atores, utilizou-se a obra organizada por Rezende, Bernardes e Araújo (2006) que apresenta os depoimentos de ex-diretores, ex-funcionários e servidores ainda na ativa. A referida publicação destaca aspectos históricos e gerenciais, situados no tempo e contextualizados pelas pessoas que vivenciaram as experiências. Constam, na obra, os depoimentos de seis exdiretores e de onze servidores técnico-administrativos (os da ativa e os aposentados), extraídos de um roteiro preestabelecido pelos organizadores para organização e apresentação das memórias dos entrevistados.

Após a coleta e a organização das informações das atividades editoriais vivenciadas pela EDUFPE e seus atores, apontam-se os três momentos editoriais da Editora e a descrição histórica dos atores e suas contribuições.

\section{$1^{\circ}$ momento editorial: a Imprensa Universitária da UFPE (1955-1971)}

- Descrição: período histórico que remonta as primeiras atividades editoriais e gráficas, com destaque para a impressão de documentos por demanda da Administração Central da UFPE, como também às publicações de obras científicas e culturais importantes para o Estado de Pernambuco.

- Diretores: Edmir Régis de Carvalho (1964 - 1966) e Moacir de Sena Dantas (1969 1982);

- Comissões Editoriais: não foram encontrados registros de comissões, pois a denominação e constituição da unidade, à época, enquanto Imprensa Universitária, não exigia a institucionalização formal dos grupos. 
$2^{\circ}$ momento editorial: a Editora Universitária da UFPE (1971-2004)

- Descrição: período histórico que evidencia a mudança do status e de organicidade da unidade acadêmica, de imprensa à editora, suas atividades e dificuldades iniciais, os investimentos da infraestrutura e, sobretudo, a formação da cultura editorial na instituição.

- Diretores: Moacir de Sena Dantas (1969 - 1982), Édison Rodrigues de Lima (1984 1992), Washington Luís Martins da Silva (1992 - 1995) e Ana Maria de França Bezerra (1996 - 2004);

- Comissões Editoriais: todas as gestões foram auxiliadas pelos Conselhos Editoriais. Contudo, observa-se que só foram encontrados registros das comissões a partir de 1995.

\section{$3^{\circ}$ momento editorial: a EDUFPE e a nova ordem digital (2004- )}

- Descrição: período histórico que consolida a cultura editorial na instituição e impõe as mudanças trazidas pelas tecnologias da informação, em especial as novas possibilidades de produção e disseminação do conhecimento.

- Diretores: Gilda Maria Lins de Araújo (2004 - 2009) e Maria José de Matos Luna (2009 $-2014)$

- Comissões Editoriais: todas as gestões foram auxiliadas pelos Conselhos Editoriais. 


\section{Considerações finais}

O surgimento das editoras universitárias no país é recente e marcado por descontinuidades e mudanças institucionais, políticas e sociais. Dos parques gráficos às imprensas universitárias, as editoras universitárias da contemporaneidade no Brasil passaram por percursos distintos, constituindo-se como instituições de excelência de disseminação do conhecimento científico sedimentado e assumindo a condição de veículo preferencial de divulgação dos atores da ciência.

A cadeia de produção e distribuição é determinada por meio das políticas editoriais, por refletirem a visão, os valores e as competências da instituição provedora (as universidades e o Estado) e exercida pela autoridade constituída, confirmando o que se expressa no referencial teórico consultado. Com efeito, a prática integrando atividades e posturas acaba por desenvolver e definir os processos de institucionalização, com seus respectivos mecanismos de controle social, suas normas e padrões de conduta. Mas os dados sugerem as mudanças significativas do comportamento resultante, especialmente decorrentes de um movimento acadêmico crítico e transformador, atuante não apenas na quantidade, mas também na qualidade dessa produção específica, caracterizado pela revisão da prática e pela criação de estruturas e projetos de alcance cultural e político. Destacam-se, nessa performance, em que também atuam forças reprodutoras, a superação histórica em relação aos anos de formação e consolidação de estruturas e práticas ainda predominantemente tipográficas. Dessa forma, a compreensão da realidade que envolve as editoras universitárias é, de um lado, de submissão às instituições provedoras, mas do outro é a de uma instituição autônoma, cujo grau de autonomia tem levado a discussões sobre as questões conflitantes relativas às atividades comerciais, de modo especial quando a elas se vincula a percepção do lucro quando se trata de uma editora de universidade pública.

No tocante aos resultados da pesquisa, verifica-se que a Editora Universitária da UFPE tem seu percurso histórico muito semelhante às demais do país, mas com pontos singulares e particulares, os quais se destacam:

a) a edição e publicação de obras e os recursos financeiros sugerem uma relação diretamente vulnerável aos problemas institucionais, sociais, políticos e econômicos do país; 
b) a lógica de produção e comunicação dos campos científicos vai se transformando ao longo do tempo e os números de publicações também são diretamente afetados;

c) as funções e os cargos na cadeia de produção e comunicação do conhecimento na EDUFPE foram exercidos não somente por docentes, mas também por técnicoadministrativos ao longo de sua trajetória de sessenta anos;

d) a ausência das políticas editoriais ao longo do tempo impossibilitou o alcance de resultados científicos consistentes e vinculados aos propósitos da Universidade;

e) os mecanismos e os instrumentos de controle de gestão documental e editorial da EDUFPE carecem de profissionalização e divulgação à comunidade;

f) as disputas e os interesses científicos são silenciosos e refletem a dinâmica institucional na busca de manutenção dos privilégios por meio dos mecanismos de reprodução social.

Por se tratar de uma pesquisa bibliográfica e documental, os resultados sinalizam uma parte do contexto e da lógica da edição certificada, pois não foi possível aprofundar a discussão dos resultados por conta da falta de acesso aos textos, além da inexistência de documentos oficiais que representam a memória institucional. Nessa perspectiva de análise, sugerem-se estudos que privilegiem:

a) a busca e a identificação dos relatórios de gestão para análise documental, de forma que a instituição possa conhecer a trajetória construída e verificar o modus operandi das decisões dos gestores;

b) a elaboração de instrumentos de controle documental e editorial para auxiliar gestores e membros dos conselhos editorial e técnico-administrativo.

Em suma, acredita-se que os objetivos traçados foram alcançados de forma satisfatória, especialmente pelo valor e significado dos acontecimentos históricos descritos como marcos para a memória e identidade institucional e cultural.

Contudo, enfatiza-se que os resultados poderiam ser melhor analisados caso o acesso a determinados documentos fosse possível. Aliado a isto, critica-se o fato da inexistência de documentos necessários para a condução de boas práticas editoriais no âmbito da atuação das editoras universitárias. 


\section{Referências}

BOURDIEU, P.; PASSERON, J. A reprodução: elementos para uma teoria do sistema de ensino. Petrópolis: Vozes, 2012.

BUFREM, L. S. (coord.). Catálogo coletivo de dicionários da língua portuguesa em bibliotecas de Curitiba. Curitiba: Departamento de Biblioteconomia da UFPR, 1993

BUFREM, L. S. Editoras universitárias no Brasil: uma crítica para a reformulação da prática. 2. ed. rev. e ampl. São Paulo: Ed. Universitária da USP, 2015.

CNPq. Tabela de Áreas do Conhecimento. [2000]. Disponível em: http://www.cnpq.br/documents/10157/186158/TabeladeAreasdoConhecimento.pdf. Acesso em: 12 maio 2020.

CUNHA, M. B. Para saber mais: fontes de informação em ciência e tecnologia. Brasília: Briquet de Lemos, 2001.

FONSECA, E. N. Bibliografia de obras de referência pernambucanas. Recife: Imprensa Universitária, 1964.

GUSMÃO, A. O. M.; MCCARTHY, C. M. Dimensionamento e avaliação da produção editorial da Editora Universitária da Universidade Federal de Pernambuco no período de 1955 a 1995. Recife: Departamento de Biblioteconomia da UFPE, 1996.

HARTNESS, A. Brasil: obras de referência, 1965-1998. Brasília: Briquet de Lemos, 1999.

HARTNESS, A. Brasil: obras de referência, 1999-2013: uma bibliografia comentada. Brasília: Briquet de Lemos, 2014.

MCCARTHY, C. M. O impacto do Mercosul sobre a editoração no Brasil. Ciência da Informação, Brasília, v. 26, n. 1, 1997. Disponível em: http://revista.ibict.br/ciinf/article/view/748. Acesso em: 16 set. 2019.

REZENDE, A. P.; BERNARDES, D. A. M.; ARAÚJO, G. M. L. (org.). EDUFPE 50 anos: histórias e perspectivas. Recife: Ed. Universitária da UFPE, 2006.

SILVEIRA, M. A. A. et al. Estudo bibliométrico de fontes sobre Pernambuco. Em Questão, Porto Alegre, v. 15, n. 1, p. 43-56, 2009.

THIESEN, I. Memória institucional. João Pessoa: Ed. Universitária da UFPB, 2013.

UFPE. Editora Universitária. 40 anos da Editora Universitária da UFPE: catálogo de publicações da Editora Universitária da Universidade Federal de Pernambuco. Recife, 1996.

UFPE. Editora Universitária. 50 anos da Editora Universitária da UFPE: catálogo de publicações da Editora Universitária da Universidade Federal de Pernambuco. Recife, 2006. 